\title{
Study on the Spatial and Temporal distributions of Physical Parameters at El Mex and Western Harbour areas, Alexandria, Egypt
}

\author{
Magdy M. Farag \\ Department of Oceanography, Faculty of Science, Univ. of Alexandria, \\ Alexandria, Egypt.
}

\begin{abstract}
$\mathrm{T}$ he western coastal water of Alexandria is affected by different drainage sources from land. This area receives fresh and brackish water from El-Mex pumping station and El-Noubareya Canal respectively. Also, domestic sewage and industrial wastes are discharged into the sea area of El-Mex and Western Harbour of Alexandria.

The main objective of this paper is to study the spatial and temporal changes of El-Mex and Western Harbour waters and monitor the plumes of different pollutants with accepted level of accuracy for practical control. This task could be executed by applying Principal Component Analysis (PCA) technique to some physical observations of sea water (temperature, salinity, density and dissolved oxygen).

The resulted PCAs from different layers of temperature, salinity, density and dissolved oxygen distributions (horizontal and vertical) showed three dominant water masses. The first water mass was found close to the shore and covered most of the water column inside the Western Harbour. Also, it extended far from the shore line to cover most of the surface layer. The second one was found at El-Dekhilla area and distributed to the northern and eastern directions. The third one was found at El-Mex Bay water, nearly covered the subsurface water and extended to offshore water. Other water masses depend on the spatial variations.

The PCAs showed that the water masses and circulation pattern inside the Western Harbour and at El-Mex Bay could be highly identified. Also, different plumes of pollutants that are discharged from land into sea could be monitored clearly.
\end{abstract}

Keywords: El-Mex Bay, Western Harbour, pollutants, physical parameters.

\section{INTRODUCTION}

The coastal zone regimes produced by the mixing of fresh water and salt water with a variety of pollutants are compound to make tracing of pollutant pathways, and pollution control extremely difficult. The oceanographic observations are important to investigate these coastal regimes and the effect of 
marine physical and dynamical process contributions to the transport of pollutants.

Alexandria city is considered the main summer resort and great economic importance to Egypt, and is the first Egyptian harbour (Western Harbour) in which about $90 \%$ of Egyptian export and import activities are done through Alexandria (Alexandria Port Authority, APA, 1978 and 1994).

The Western Harbour and El-Mex Bay are the most polluted spots in the Egyptian northern coast (Aboul-Dahab, 1983; Tadros and Nessim, 1988; Said et al., 1990; Shiriadah and Tayel, 1992). El-Mex Bay receives a continuous direct discharge of industrial and agricultural drainage water of about 6-11.8 million $\mathrm{m}^{3} /$ day, carrying agro-chemicals, trace metals, and domestic waste (El-Awady, 1972; Nessim and Tadros, 1986; El-Sherif 1989; Said et al., 1991; Abdel Aziz and Gharib, 2007). The wastes dumped from the ship traffic to and from Alexandria's Western Harbour, together with those from the large number of fishing boats add their effects to the water quality of El-Mex Bay (Aboul-Dahab, 1983 , Saad et al., 1993; Nessim, 1994). Also, the volume of discharged water from El-Umum (U.D.) Drain to El-Mex Bay during 2003 was about three times more than that discharged before - during 1982 and 1995 (Abdel Aziz, 2002; Mahmoud et al., 2005; Zakaria et al., 2007).

The Western Harbour and El-Mex Bay receive large amount of organic and inorganic pollutants. These pollutants have a severe effect on the water quality and the associated aquatic ecosystem (Saad et al., 1993; Nessim, 1994). El-Mex Bay receives a heavy load of wastewater directly from industrial outfalls and indirectly from Lake Mariout via El-Mex Pumping Station and El-Umum Drain. The main outfalls discharges are Misr Chemical Industries effluents, the combined wastewater effluent from the Tanneries (About sixteen factories lie on the sea side at El-Mex), Slaughter House, Alexandria Iron and Steel factory, ElNoubareya Canal (N.C.), El-Mahmoudeya Canal (M.C.) and El Terssan outfalls (Said et al., 1991). Nessim and Tadros (1986), Emara and Shiriadah (1991) have studied the effects of industrial pollutants on El-Mex Bay water, sediments and some marine organisms, and detected the severe effect of industrial pollutants on the water quality parameters.

\section{Aim of the Work}

The use of PCA technique, to assess the spatial and temporal distributions of the sea water physical properties and circulation patterns in the Western Harbour and El-Mex Bay, is the main objective of this study because of its advantage and relative high accuracy process. In particular, the main aims are to: 1) monitoring the pollutant plumes that have been caused by the industrial activities at El-Mex bay and the Western Harbour, 2) estimating the effect of the physical parameters (Temperature, Salinity, density and dissolved Oxygen) to the variability of sea water column at the study area, and 3) introducing the best spatial and temporal scales for analysis. 


\section{Study Area}

\section{MATERIAL AND METHODS}

The study area lies at the west of Alexandria between latitudes $31^{\circ} 07^{\prime} \mathrm{N}$; $31^{\circ} 13^{\prime} \mathrm{N}$ and longitudes $29^{\circ} 47^{\prime} \mathrm{E} ; 29^{\circ} 53^{\prime} \mathrm{E}$ (Fig.1). This interested area includes the Western Harbour and El-Mex Bay. The Western Harbour proper is elliptical in shape having a length of $7 \mathrm{~km}$ and a maximum width of $2 \mathrm{~km}$ with covered area about $31 \mathrm{~km}^{2}$ (Alexandria Port Authority, APA, 1994).

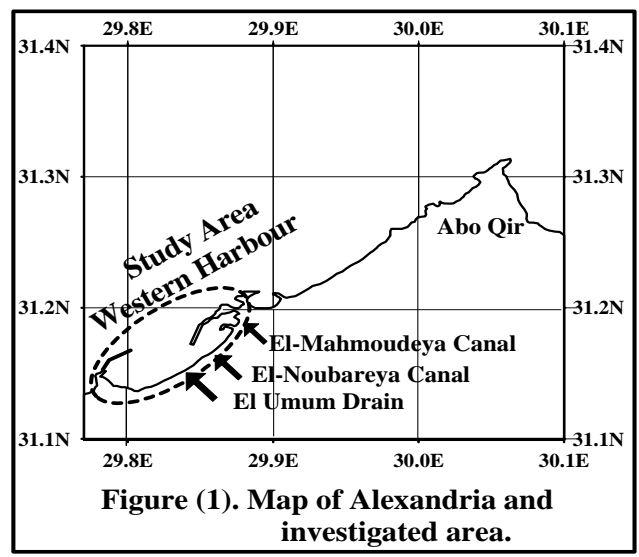

The Western Harbour is divided into two parts, the Inner Harbour and Outer Harbour, separated by the line running across the coal quays (Fig 2).

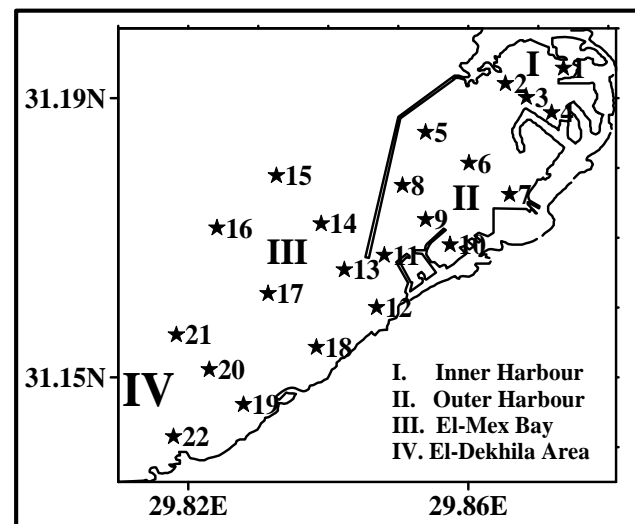

Figure (2). Sampling locations.

El-Mex Bay is dominated by on eastward current, and a less powerful one westward close to the coast. This surface circulation pattern has been explained as being induced by prevailing northwest and southwest winds (Farag, 1982). The direction and rate of exchange between El-Mex Bay and Western Harbour is 
controlled by the mixing of surface sea water with runoff water from El-Mex Pumping Station and El-Noubareya Canal and other sources.

The area between El-Mex Bay and Western Harbour is also affected by the discharge of drainage water from El-Umum Drain and the main sewer. The powerful outflow from El-Umum Drain creates a strong offshore surface current, and as a result there is a sub-surface compensation current of higher salinity near the bottom directed towards the coast (Farag, 1982).

\section{Measurements and Analysis}

The hydrographic observations (temperature, salinity, density and dissolved oxygen) that have been sampled from El-Mex and Western Harbour areas as a part of the survey to study the pollution dispersion during 1980 and 1981 (Farag, 1982) will be used as input information to execute the main objective of this study. Untraditional methods are needed for monitoring surface and subsurface circulation, water quality distributions and understanding of the dynamic regime.

The hydrographic observations were taken from 22 stations, distributed equally at the Western Harbour and El-Mex Bay areas, nearly every month during the period from June 1980 to June 1981 (Fig. 2). The first 11 stations covered the Western Harbour area, and the other 11 stations were distributed at El-Mex Bay and the industrial discharge (I.d.) area at El-Dekhela. The temperature, salinity, density and dissolved oxygen observations were measured and sampled at each station from depths surface, $5 \mathrm{~m}$ and $10 \mathrm{~m}$, and re-tabulated according to different scales for using PCA technique.

Principal Component Analysis (PCA) is an important data transformation technique used in multidimensional data (Mulder and Hempenius, 1974 and Richards, 1984). Principle Components Analysis technique is a powerful tool for introducing temporal and spatial information about pollution qualitative (concentrations, locations, and its levels that can influence the marine environment) and dominant circulation patterns. This information is important for the decision-makers and environmental protection policies.

The principal component transformation that referred to the eigenvector transformation is a redundancy reduction technique. The main advantages of PCA are: 1) Describing multidimensional data with first variable (or component) contains most variance, 2) Succeeding components contain decreasing proportions of data scatter (Jenson and Waltz 1979, Gonzalez and Wintz, 1987), and 3) It has valuable enhancements to the regions of localized changes in multiparameter data (Yamagata and Akiyama, 1988). The loading of the eigenvectors have been used to describe the relative contributions of each original parameter to the transformed components. The data of the original parameters are redistributed, by means of a linear transformation of data variables, among the same number of new parameters.

The principal components are usually calculated from a variance-covariance matrix. Clearly, the covariance terms indicate the degree of inter-correlation, and the principal components are not invariant under the linear transformation 
including separate scaling of the original variables. Principal component analysis is considered to be a complicated mathematical procedure, and the transformed data can be interpreted directly by reference to the distribution of data in feature space.

The collected data were analyzed by using PCA technique according to different multi-scales. These scales are time scale (annual and seasonal), depth scale (surface and subsurface waters, 0, 5 and 10m depths), parameters scale (temperature, salinity, density, dissolved oxygen and total parameters) and spatial scale (horizontal and vertical). All the acquired data were rearranged and organized in different groups according to their average values of each scale and location (latitude and longitude) of each station individually for horizontal and vertical distributions study. The results of all groups' analysis will introduce too much PCAs that couldn't be established here easily. Thus, this study will introduce the most important resulted PCAs from all scales and groups.

\section{RESULTS AND DISCUSSION}

Discussion of the main important PCA results, according to the spatial scale (location and depth) and temporal scale (annual and different seasons), will be introduced here in details as follows:

\section{Horizontal distributions}

\section{a. Sea water temperature}

Figure (3) represents the horizontal spatial distribution of PC1- $t_{d}$ levels resulted from analyzing the annual averages of temperature at each depth (surface, $5 \mathrm{~m}$ and $10 \mathrm{~m})$ at each station $\left[\right.$ PC1- $\mathrm{t}_{\mathrm{d}}(45 \%)=-0.206 \mathrm{D} 0+0.656$ D5 + 0.574 D10].

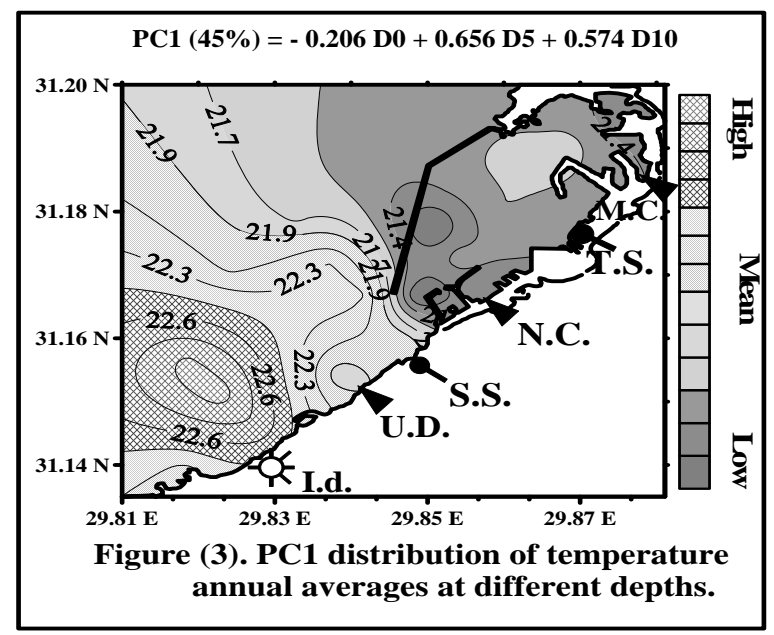

The eigen-value of this PC1- $t_{d}$ was $45 \%$, i.e. this PC1- $t_{d}$ introduced about $45 \%$ of the total variations of temperature. The distribution of PC1- $t_{d}$ levels 
showed that the high levels (light) located at El-Dekhila area. According to the eigen-vector coefficient (0.656), this area was highly affected by variations of temperature at subsurface water (5m depth). Also, the PC1- $\mathrm{t}_{d}$ levels at El-Mex area which were estimated by eigen-vector coefficient (0.574) represented most of the sea water temperature distribution at deep water $(10 \mathrm{~m})$.

Figure (3) shows that the lower levels (dark) covered all the Western Harbour area and represented PC1- $t_{d}$ levels by eigen-vector coefficient $(-0.206)$. This coefficient indicated that most of temperature variations inside the Western Harbour were found at the surface layer.

Finally, Figure (3) indicates that the Western Harbour and El-Dekhila areas are characterized by variations of annual averages of water temperature at the surface and $5 \mathrm{~m}$ respectively. Also, annual averages distribution of water temperature at El-Mex Bay area was affected by U.D. and S.S. at subsurface water.

Figure (4) represents the spatial distribution of PC1- $\mathrm{t}_{\mathrm{s}}$ levels resulted from analyzing the seasonal averages of temperature at each station $\left[\right.$ PC1 $-\mathrm{t}_{\mathrm{s}}(60 \%)=$ $0.033 \mathrm{Su}+0.196 \mathrm{Au}+0.007 \mathrm{Wi}+0.307 \mathrm{Sp}$ ]. The eigen-value of these PC1- $\mathrm{t}_{\mathrm{s}}$ indicated that $60 \%$ of total variations included at this principal component. The eigen-vector coefficients (0.033 and 0.007) of PC1- $\mathrm{t}_{\mathrm{s}}$ showed that the area of low levels (dark) that covered the northern part of the Western Harbour represented temperature variations during summer and winter seasons.

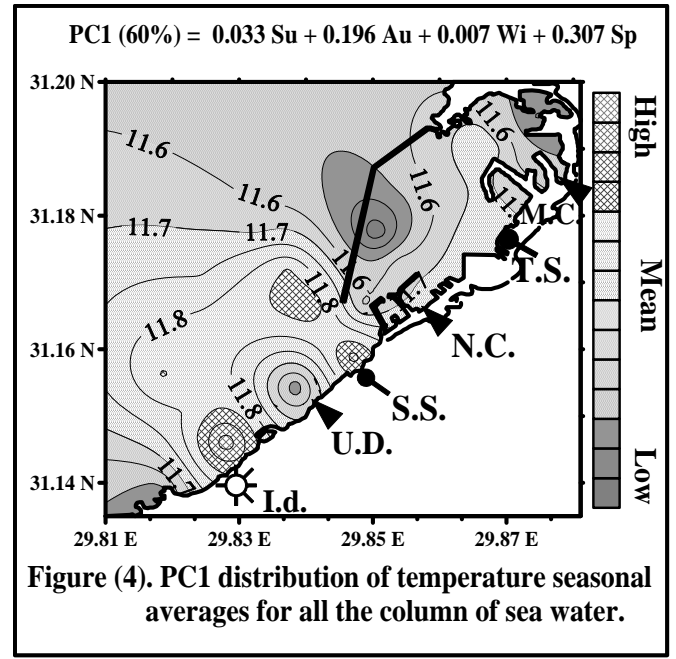

The higher levels (light) were found at coastal water inside the Western Harbour and outside it. These levels represented temperature variations during spring and autumn seasons. Finally, Figure (4) shows three different spot areas (S.S, U.D. and Id) outside the Western Harbour, each area had different seasonal temperature variability. 


\section{b. Sea water salinity}

Figure (5) represents the spatial distribution of PC1- $\mathrm{s}_{\mathrm{d}}$ levels resulted from analyzing the annual average of salinity at each depth (surface, $5 \mathrm{~m}$ and $10 \mathrm{~m}$ ) $\left[P C 1-\mathrm{S}_{\mathrm{d}}(94 \%)=0.817\right.$ D0 + 0.273 D5 + 0.253 D10]. The eigen-value of PC1- $\mathrm{s}_{\mathrm{d}}$ (94\%) represented most of salinity variations at different depths with higher contribution from surface distributions.

The eigen-vector of PC1-s showed that the area of low levels (dark) located at El-Mex Bay and coastal water inside the Western Harbour areas. These low levels represented the subsurface water with eigen-vector coefficients (0.273 and 0.253). Also, PC1-s (Fig. 5) indicated that the dominated variations that happened at the low levels (dark) area represented the changes of subsurface water ( $5 \mathrm{~m}$ and $10 \mathrm{~m}$ depths), and this distribution was affected by U.D. and S.S. The low levels inside Western Harbour water covered the coastal water that affected by M.C., T.S. and N.C. at subsurface water.

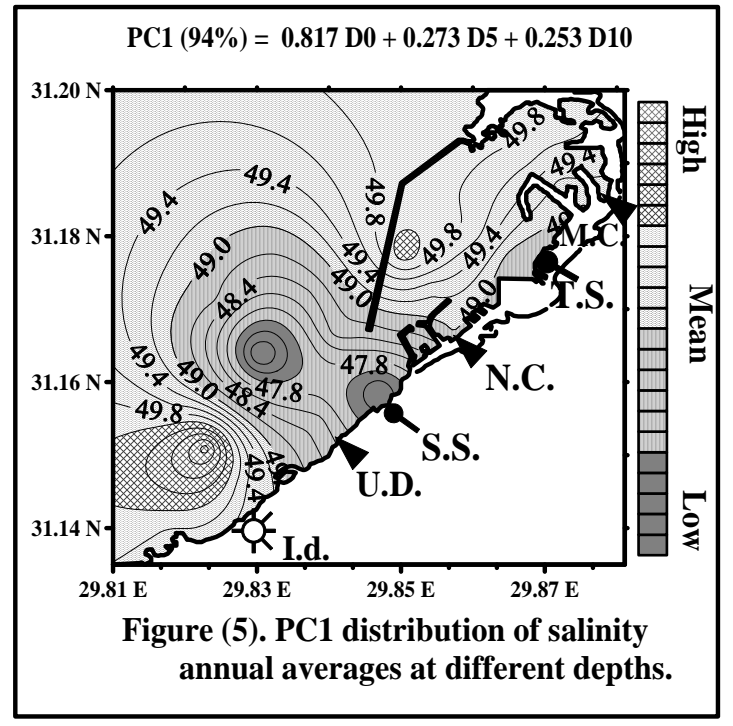

Finally, Figure (5) show that the study area could be divided into three areas as follows: 1) inside Western Harbour water that is characterized by middle levels of PC1-s and mostly affected by fresh water, 2) El-Dekhila area that is characterized by high levels of PC1- $\mathrm{s}_{\mathrm{d}}$ and distributed over the surface water, i.e. the highest effect of salinity is at surface water at this area, and 3) El-Mex area was characterized by lower PC1- $\mathrm{s}_{\mathrm{d}}$ levels and distributed at subsurface water, i.e. the subsurface water is more affected by salinity distribution at this area.

Figure (6) represents the spatial distribution of $\mathrm{PC} 1-\mathrm{s}_{\mathrm{s}}$ resulted from analyzing seasonal salinity averages of each station $\left[\mathrm{PC} 1-\mathrm{s}_{\mathrm{s}}(90 \%)=0.025 \mathrm{Su}+\right.$ $0.013 \mathrm{Au}+0.049 \mathrm{Wi}+0.013 \mathrm{Sp}$. The eigen-value of PC1- $\mathrm{s}_{\mathrm{s}}$ equals $90 \%$, of the total salinity variance. The eigen-vector of $\mathrm{PC} 1-\mathrm{s}_{\mathrm{s}}$ showed that the area of low 
levels (dark) located at the western water of El-Mex Bay area was affected by S.S. discharge, and most of its variability was during autumn and spring seasons.

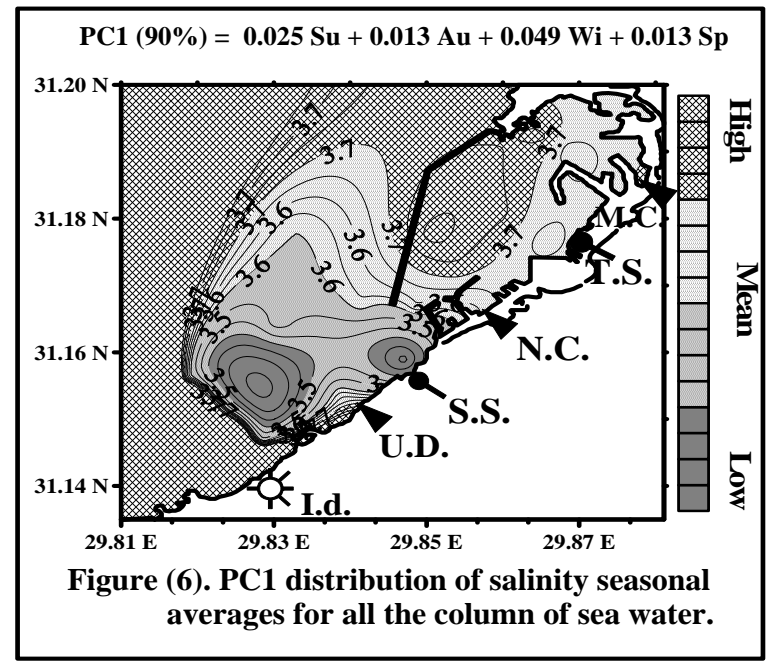

Also, PC1-s $\mathrm{s}_{\mathrm{s}}$ areas of high levels (light) located at El-Dekhilla area represented summer and winter salinity distribution. This distribution showed that industrial discharge (I.d.) was the most affecting to salinity distribution in this area. The eigen-vector coefficients of PC1- $\mathrm{s}_{\mathrm{S}}$ showed that this area of high levels (light) was highly affected by the discharge during summer and winter seasons.

Finally, Figure (6) indicates that most of the coastal waters inside and outside the Western Harbour showed variability winter and summer, and autumn and spring seasons respectively.

\section{c. Sea sater density}

Figure (7) represents the spatial distribution of PC3- $d_{d}$ resulting from analyzing the annual average of sea water density at different depths (surface, $5 \mathrm{~m}$ and $10 \mathrm{~m})$ [PC3- $\mathrm{d}_{\mathrm{d}}(2 \%)=0.153$ D0 + 0.987 D5 - 0.018 D10]. The eigenvalue of PC3- $\mathrm{d}_{\mathrm{d}}(2 \%)$ represented very low percentage variations but introduced valuable information.

The PC3- $\mathrm{d}_{\mathrm{d}}$ levels showed that the area of high levels (light) located inside the Western Harbour area, and represented the highly affected area by N.C. discharges. According to the eigen-vector coefficient (0.987), the high levels represented most of the density distribution at the subsurface water ( $5 \mathrm{~m}$ depth) inside the Western Harbour. 


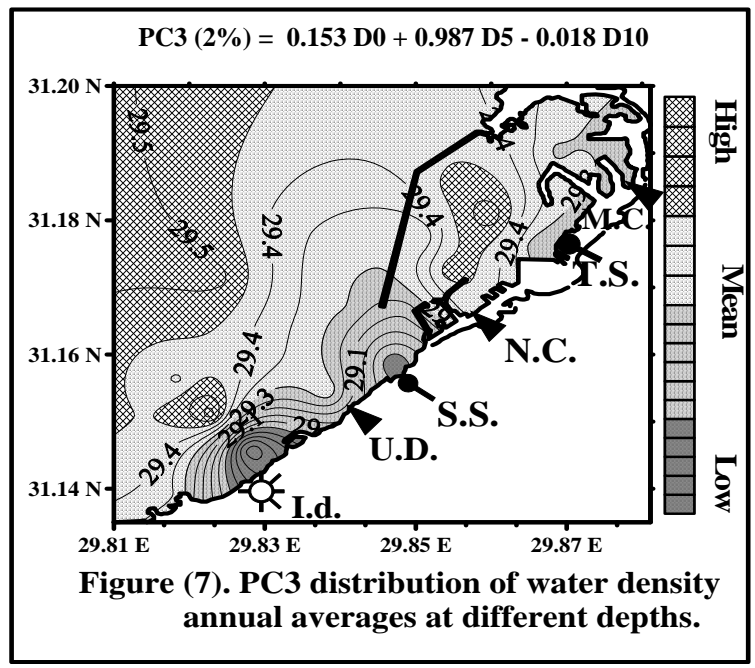

Also, Figure (7) shows that the low levels (dark) represented the coastal water outside the Western Harbour area. The eigen-vector coefficient $(-0.018)$ indicated that the density distribution of subsurface water was highly affected by S.S, U.D. and I.d. discharges.

Figure (8) represents the spatial distribution of $P C 1-d_{s}$ resulted from analyzing seasonal averages of density at each station $\left[\mathrm{PC} 1-\mathrm{d}_{\mathrm{s}}(77 \%)=-0.144\right.$ $\mathrm{Su}+0.326 \mathrm{Au}-0.453 \mathrm{Wi}-0.209 \mathrm{Sp}$. The eigen-value of PC1- $\mathrm{d}_{\mathrm{s}}$ equals $77 \%$, of the density variations. The eigen-vector of PC1- $\mathrm{d}_{\mathrm{s}}$ showed that the area of low levels (dark) located at the offshore water of the Western Harbour (Inner Harbour) and the western water of El-Dekhilla area. The eigen-vector indicated that the PC1- $d_{s}$ low levels (dark) at these areas represented lower than $77 \%$ distributions of the winter, spring and summer seasons. These areas are affected by M.C. discharges inside inner harbour and by I.d. discharges in El-Dekhilla area.

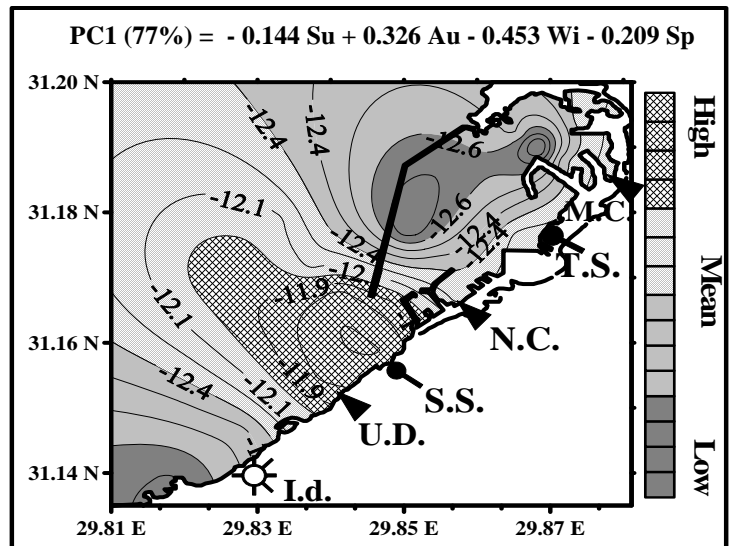

Figure (8). PC1 distribution of density seasonal averages for all the column of sea water. 
Also, PC1- $\mathrm{d}_{\mathrm{s}}$ areas of high levels (light) represented about $77 \%$ of the autumn distribution. This distribution showed the sources that have effected to density distribution at coastal water of Western Harbour and whole El-Mex Bay areas. These areas are highly affected by the inland discharges from T.S., N.C., S.S. and U.D. .

Finally, Figure (8) indicats that most of the coastal water inside and outside the W.H. had $77 \%$ density changeability during autumn.

\section{d. Dissolved oxygen}

Figure (9) represents the spatial distribution of $\mathrm{PC} 1-\mathrm{O}_{\mathrm{d}}$ resulting from analyzing the annual averages of dissolved oxygen at different depths $\left[\mathrm{PC} 1-\mathrm{O}_{\mathrm{d}}\right.$ $(76 \%)=0.357 \mathrm{D} 0+0.835 \mathrm{D} 5-0.333 \mathrm{D} 10]$. The eigen-value of $\mathrm{PC} 1-\mathrm{o}_{\mathrm{d}}$ was $76 \%$, i.e. it contained about $76 \%$ of total dissolved oxygen variability. Figure (9) shows three different interesting areas. The first was characterized by lower levels (dark) at the Inner Harbour, coastal water of outer Harbour and El-Dekhilla waters which are affected by M.C. and N.C. inside the Western Harbour, and I.d. outside it. The second was characterized by higher levels (light) at El-Mex Bay.

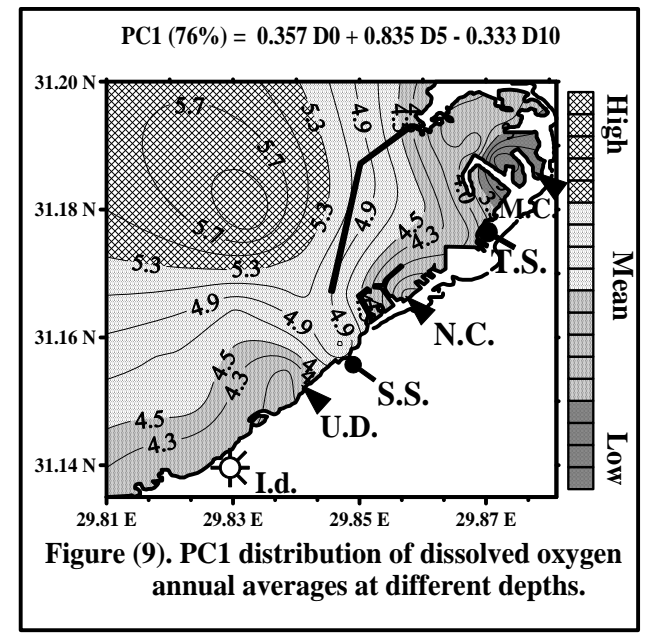

The eigenvector coefficient $(-0.333)$ of PC1- $\mathrm{O}_{\mathrm{d}}$ showed the area of low levels (dark) which represented subsurface water $(10 \mathrm{~m})$ and the coefficients $(0.357$ and 0.835) showed the area of high levels (light) which are characterized by higher variability of dissolved oxygen at surface water. Finally, figure (9) shows $76 \%$ of dissolved oxygen distribution at different layers inside and outside the Western Harbour, and introduced the more affected areas by land discharges obviously.

Figure (10) represents the spatial distribution of $\mathrm{PC} 1-\mathrm{O}_{\mathrm{s}}$, resulting from seasonal average of dissolved oxygen at each station, with eigen-value equals $98 \%\left[\mathrm{PC} 1-\mathrm{o}_{\mathrm{s}}(98 \%)=-0.324 \mathrm{Su}+0.123 \mathrm{Au}-0.030 \mathrm{Wi}-0.559 \mathrm{Sp}\right]$. The eigen- 
vector of PC1- $\mathrm{O}_{\mathrm{s}}$ showed that the area of high levels (light) covered the Western Harbour and represented autumn season distributions. Also, the eigen-vector coefficients showed the lower levels (dark) distribution which covered all waters outside the Western Harbour. These levels represented the summer and spring variability of dissolved oxygen.

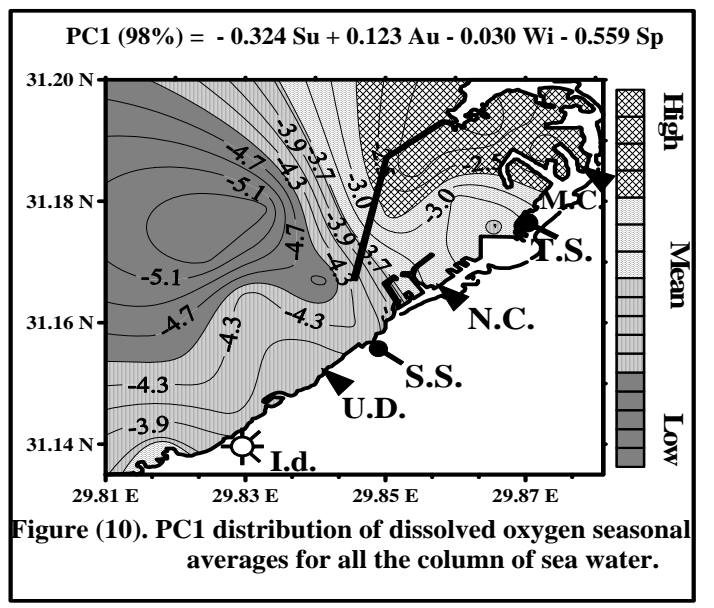

Finally, Figure (10) indicateds that the dissolved oxygen distribution at the study area had two different seasonal patterns. The first one was found inside the W.H. and represented autumn distribution, and affected by N.C. and T.S. discharges. The second was found outside the W.H. representing summer and spring distributions, and affected by S.S., U.D. and I.d. discharges.

\section{e. Total parameters}

Figure (11) represents the spatial distribution of PC1- $\mathrm{t}_{\mathrm{p}}$ resulting from analyzing the total annual averages of each physical parameters (Temperature, Salinity and Density) at each station $\left[\right.$ PC1- $\mathrm{t}_{\mathrm{p}}(94 \%)=0.085 \mathrm{Tmp}-0.069 \mathrm{Sal}+$ 0.209 Den]. The eigen-value of PC1- $t_{p}$ was $94 \%$, representing about $94 \%$ of the information about the distributions of physical parameter at each individual station.

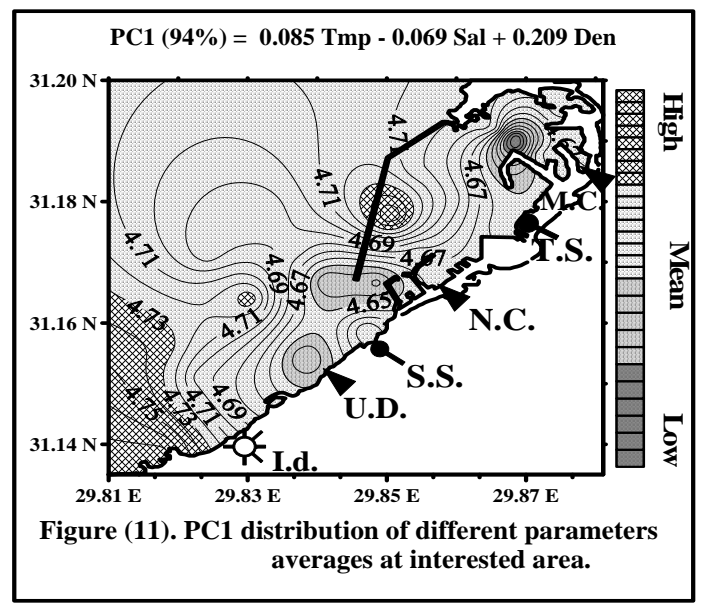


The distribution of PC1- $t_{\mathrm{p}}$ levels showed that the area of low levels (dark) covered three areas as follows: 1) Inner Harbour (near M.C), 2) Outer Harbour (near N.C.), and 3) EL-Mex Bay (near U.D.). The eigen-vector coefficient $(-0.069)$ of PC1 $-t_{p}$ indicated that the above areas were more affected by salinity distribution. The eigen-vector coefficient (0.209) indicated that the area of high levels (western part of El-Dekhilla - I.d.) was more affected by sea water density distributions.

\section{Vertical distributions}

This part introduces PCA of vertical distribution resulting from the annual averages of each parameter at each station and depth. The vertical distribution results represented three sections (coastal, middle and off-shore) as follows: 1 ) coastal stations (1, 4, 7, 10, 11, 12, 18, 19 and 20), 2) middle stations (1, 3, 6, 9, 11, 13, 17, 20 and 22) and 3) off-shore stations (1, 2, 5, 8, 11, 13, 16, 21 and 22).

\section{a. Coastal section}

Figure (12 top) represents the coastal vertical distributions of PC1- Cs $_{p}(69 \%)$ resulting from analyzing the annual average of each parameter at each station and depth [PC1-cs $(69 \%)=0.065 \mathrm{Tmp}-0.103 \mathrm{Sal}+0.063$ Den $-0.049 \mathrm{Oxg}+$

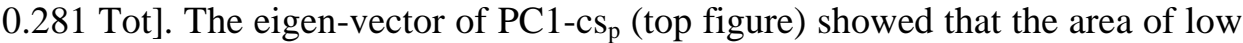
levels (dark) covered most of the surface and subsurface coastal water inside the Western Harbour area and the surface water at El-Mex Bay. The eigen-vector coefficient (-0.103) represented the salinity effects as dominant parameter. While the high levels (light) represented most of subsurface water $(5 \mathrm{~m}$ and $10 \mathrm{~m}$ depths) variations at El-Dekhila area, and characterized by high affects of the total averages of all parameters. These high levels (light) covered subsurface water at this area and going up to the surface water and shifted toward the east direction.

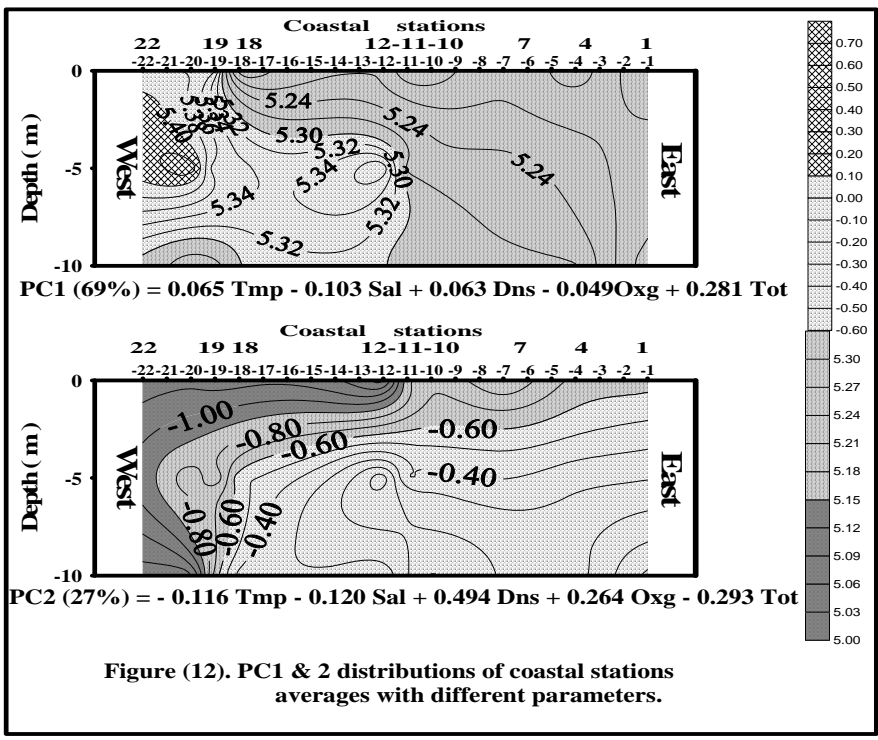


Figure (12, bottom) representing the vertical distribution of PC2-Cs (27\%) $\left[\mathrm{PC} 2-\mathrm{Cs}_{\mathrm{p}}(27 \%)=-0.116 \mathrm{Tmp}-0.120 \mathrm{Sal}+0.494\right.$ Den -0.264 Oxg -0.293 Tot]. The eigen-vector of this $\mathrm{PC} 2-\mathrm{Cs}_{\mathrm{p}}$ indicated that the middle levels represented most of the surface and subsurface water inside and outside the Western Harbour. Also, figure (12 bottom) shows that the subsurface water at stations 18 and 19, highly affected by I.d. discharges. The vertical distribution of this water showed that this water was going up, and shifted to east direction. It means that El-Ummum Drain (U.D.) and Industrial discharges waters (I.d.) that appeared at the surface water located to the east of outfall of U.D.

\section{b. Middle section}

Figure (13 top) represents the middle vertical distributions of PC1- $\mathrm{md}_{\mathrm{p}}$ (69\%) resulted from analyzing the annual average of each parameter at each station and depth $[$ PC1-md $(69 \%)=0.065 \mathrm{Tmp}-0.103 \mathrm{Sal}+0.063 \mathrm{Den}-0.049$ Oxg +0.281 Tot]. The eigen-vector of PC1- $\mathrm{md}_{\mathrm{p}}$ (top figure) showed that the area of low levels (dark) covered the surface water inside the Western Harbour and El-Mex areas. These areas characterized by high water salinity and dissolved oxygen variability.

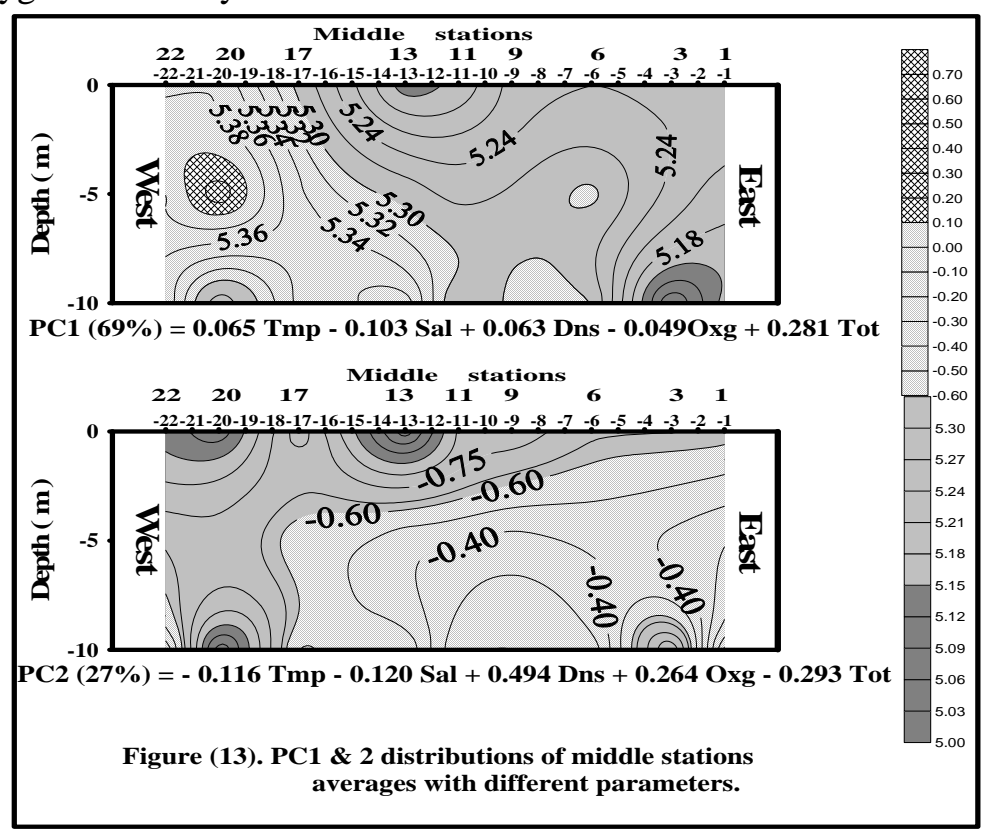

The high levels (light) of PC1-md $\mathrm{p}_{\mathrm{p}}$ represented most of surface and subsurface water variations at El-Dekhilla. These high levels characterized by higher variability of total parameters average (eig-vec. coeff. $=0.281$ ). The light area introduced, in clear manner, the subsurface upwilling water between station 10 (front of El-Noubareya Canal) and station 6 (middle area of Outer Harbour). 
This upwilling caused nearly shifting water from the bottom water at station 10 to the surface water at station 6 at east.

Figure (13 bottom) represents the middle vertical distribution of PC2-md $(27 \%)\left[\right.$ PC2 - md $_{p}(27 \%)=-0.0116 \mathrm{Tmp}-0.120 \mathrm{Sal}+0.494 \mathrm{Den}+0.264 \mathrm{Oxg}-$ 0.293 Tot]. The eigen-vector of this PC2- $\mathrm{md}_{\mathrm{p}}$ indicated that the light area represented higher water density and dissolved oxygen variability (eig-vec coeffs. $=0.494$ and 0.264 ). The PC2-md low levels (dark) were found to cover the surface and subsurface areas at El Dekhilla. The eigen-vector coefficients ( $0.116,-0.120$ and -0.293 ) indicated that the more affected parameters at the dark area were water temperature and salinity.

\section{c. Off-shore section}

Figure (14 top) represents the off-shore vertical distributions of PC1-of (69\%) and PC2-of $(27 \%)$ resulted from analyzing the annual average of each parameter at each station and depth $\left[\mathrm{PC} 1-\mathrm{of}_{\mathrm{p}}(69 \%)=0.065 \mathrm{Tmp}-0.103 \mathrm{Sal}+\right.$

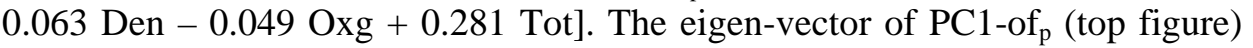
showed that the area of low levels (dark) covered most the water at El-Dekhilla area with more affected by water salinity and dissolved oxygen (eig-vec. coeffs. $=-0.103$ and -0.049 ).

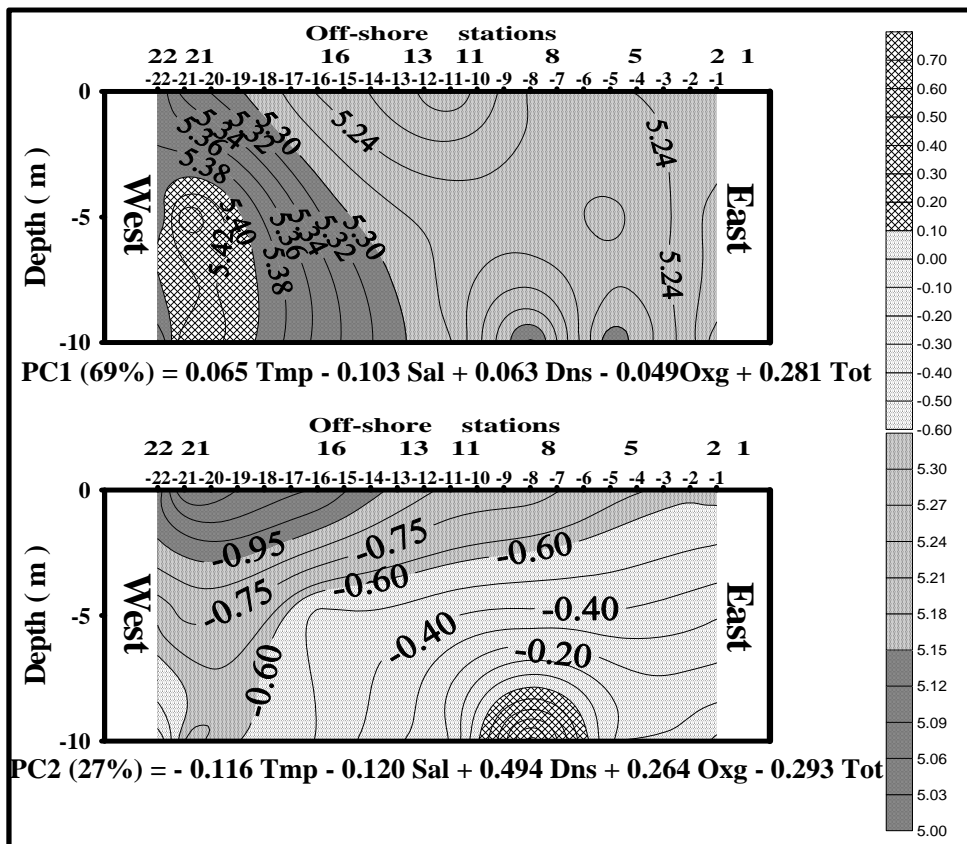

Figure (14). PC1 \& 2 distributions of deep stations averages with different parameters. 
The middle levels area represented the surface and subsurface water inside the Western Harbour and at El-Mex areas, with more affected by water temperature and density (eig-vec. coeffs. $=0.065$ and 0.063 ). The high levels of PC1-of $\mathrm{p}_{\mathrm{p}}$ covered narrow subsurface water area at ElDekhilla (station 21 and 22) and more affected by I.d discharges.

Figure (14, bottom) represents off-shore vertical distribution of PC2-of (27\%) $\left[\right.$ PC2-of ${ }_{\mathrm{p}}(27 \%)=-0.116 \mathrm{Tmp}-0.120 \mathrm{Sal}+0.494$ Den +0.264 Oxg 0.293 Tot]. The vertical distribution of low levels (dark) showed that this water was found to cover surface and subsurface water outside of the Western Harbour of this section area with higher stratification. The light area covered small subsurface area inside the Western Harbour.

Finally, the main PCA results of different vertical distributions introduced more clearness about vertical distributions of different physical parameters, which indicated the complicated circulation patterns at the interested area. These patterns have been affected more or less by U.D. and S.S. and I.d. discharges.

\section{Conclusions}

It could be concluded that the investigated area has three different areas with three different water masses as follows: 1) Inner Harbour and most of Outer Harbour area: It is more affected by salinity distribution at surface and subsurface area, especially during summer and winter seasons. This areas more affected by the discharges from M.C., T.S. and N.C., 2) Western area: more affected by temperature and dissolved oxygen distributions at subsurface water, especially during spring season. This area is highly affected by Industrial and U.D. discharges, and 3) Middle area: located between the first and second areas, and covered the area around the main entrance of Western harbour. This area is highly influenced by U.D. and S.S. discharges.

Also, the principal component analysis technique was highly useful for studying horizontal and vertical distributions of physical parameters, and circulation patterns of the investigated area.

\section{REFERENCES}

Aboul-Dahab, O.M.T. (1983). Environmental conditions in Mex Bay, west of Alexandria physical spoliation of four traces metals in the Bay. VII's Jounces Etude. Pollution, Lucerne, C.I.E.S.M.: pp. 347 - 355.

Abdel Aziz, N.E. (2002). Impact of water circulation and discharge wastes on zooplankton dynamics in the Western Harbour of Alexandria, Egypt. Egypt. J. Aquat. Biol. \& Fish, 6(1): 1 - 21. 
Abdel Aziz, N.E. and Gharib, S.M. (2007). Food and feeding habits of round Sardinella (Sardinella aurita) in El Mex Bay, Alexandria, Egypt. Egypt. J. Aquatic Research, 33(2): 202 - 221.

Alexandria Port Authority (1978 and 1994). Ministry of Maritime Transport. Special reports for description of the harbor, 27 pp. (In Arabic).

El- Awady, M.M. (1972). The physical and chemical properties of Alexandria Harbour water relevant to fouling paints. M.Sc. Thesis, Cairo Univ., 217pp.

El-Sherif, Z.M. (1989). Distribution and ecology of phytoplankton in El-Mex Bay, Egypt. Bull. Inst. Oceanogr. \& Fish., ARE, 15(2) : 83-100.

Emara, H.I. and Shiriadah, M.A. (1991). Manganese, Iron, Cobalt, Nickel and Zinc in the Eastern Harbour and El-Mex Bay waters (Alexandria). Proc. Symp. Mar. Chem. In the Arab Region, Suez : 99-112

Farag, M.M. (1982). Circulation patterns and hydrographic structure of El-Mex and Western Harbour areas. M.Sc. Thesis, Alex. Univ. Faculty of Science, 276 p.

Gonzalez, R.C. and Wintz, P. (1987). Digital image processing. Second Edition. Addison-Wesley Publishing Company, 503 pp.

Jenson, S.K. and Waltz, F.A. (1979). Principal components analysis and canonical analysis in remote sensing. Proc. Am. Soc. Photogr. $45^{\text {th }}$ Ann. Meeting: pp.337-348.

Mahmoud, Th.H.; Masoud, M.S. and Shaltout, N.A. (2005). Physico-chemical characteristics of different water types in El-Mex Bay, Alex., Egypt. Conference MTS/IEEE Ocean 2005, Washington, D.C. USA.

Mulder, N.J. and Hampenius, S.A. (1974). Data compression and data reduction techniques for the visual interpretation of multispectral images. ITC Journal, 3: 414-423.

Nessim, R.B. and Tadros, A.B. (1986). Distribution of nutrient salts in the water and pore water of the Western Harbour of Alexandria, Egypt. Bull. Nat. Inst. Oceeanogr. \& Fish., ARE, 12 : 165 - 174.

Nessim, R.B. (1994). Environmental characteristics of Mex Bay. $1^{\text {st }}$ Proc. Arab Conf. on Marine Environment Protection. Alexandria : pp. 221-243. 
Richards, J.A. (1984). Thematic mapping from multitemporal image data using the principal components transformation. Remote Sensing of Environm., $16: 35-46$.

Saad, S.G.; Abouzid, G.; Saad, L.M. and Mitwally, H. (1993).Impact of pollution in Alexandria Harbour. Bulletin of the High Institute of Public Health, 23 (3): 627-642.

Said, M.A.; El-Deek, M.S.; Mahmoud, Th.H. and Shriadah, M.A. (1990). Effects of pollution on the hydro-chemical characteristics of different water types in El-Mex Bay area west of Alexandria, Egypt. C.I. E.S.M., Perignan, France : pp.15-22.

Said, M.A.; El-Deek, M.S.; Mahmoud, Th.H. and Shiariadch, M.M.A. (1991). Physico-chemical characteristics of different water types of El-Mex Bay, Alexandria, Egypt. Bull. Nat. Inst. Oceanogr. \& Fish., ARE, 17 (1): 103 - 116.

Shiriadah, M.M.A. and Tayel, F.T.R. (1992). Environmental condition of the Western Harbour of Alexandria. 1) physico-chemical characteristics. Bulletin of the High Institute of Public Health, 22 (1): 213 - 230.

Tadros, A.B. and Nessim, R.B. (1988). The occurrence and distribution of some trace elements in Alexandria Western Harbour. $2^{\text {nd }}$ Chemistry Conference, Fac. of Sci., Alex. Univ.: pp. 221- 239.

Yamagata, Y. and Akiyama, T. (1988). Flood damage analysis using multitemporal Landsat Thematic Mapper data. Int. J. Remote Sensing, 9(3): 503-514.

Zakaria, H.Y.; Radwan, A.A. and Said, M.A. (2007). Influence of salinity variations on zooplankton community in El-Mex Bay, Alexandria, Egypt. Egypt. J. Aquatic Res., 33(3): 52-67. 